\title{
ARTIGO
}

\section{Fator de Risco Ruído: \\ Barulho Normativo e Silêncio Governamental}

Risk factor noise: "normative noise" and governmental silence

Factor de riesgo: ruido normativo y silencio gubernamental

\section{Paulo Rogério Albuquerque de Oliveira ${ }^{1}$}

RESUMO: Este artigo aborda de forma crítica e propositiva a inércia governamental quanto à necessária harmonização dos parâmetros, metodologia, procedimentos e limites de tolerância pertinentes ao fator de risco ruído. No âmbito do governo federal, há uma anômala bifurcação do ponto de vista jurídico-normativo, bem como técnico-procedimental de avaliação e tolerância ao ruído, pois o que vale para a Receita Federal do Brasil - RFB e Instituto Nacional de Seguro Social - INSS não vale para o Ministério do Trabalho $\mathrm{MTb}$, de forma que o direito à redução no tempo de contribuição para 25 anos junto ao INSS e o respectivo recolhimento pela empresa à RFB, de 6\% da remuneração do trabalhador, seguem regra da NHO-01 da Fundacentro, enquanto o pagamento de adicional de remuneração pela empresa (20\% do salário mínimo) ao trabalhador adota o anacrônico, evasivo e equivocado Anexo I da NR15. Faz-se um apanhado histórico, inclusivo normativo, que contextualiza e

1 Doutor em Ciências da Saúde (UnB), Auditor-Fiscal da Receita Federal do Brasil, Secretaria de Previdência do Ministério da Fazenda.

Laborare. Ano I, Número 1, Julho/2018, pp. 85-117. ISSN 0000-0000. http://trabalhodigno.org/laborare 
explica o procedimento fiscal e o reconhecimento de direitos adstritos ao ruído. Discorre-se sobre a definição e significados dos principais parâmetros de avaliação (Critério de Referência - CR, Fator de Dobra (q) e Nível Limiar de Integração - NLI). Apresentam-se exemplos práticos que evidenciam as consequências nefastas ao trabalhador decorrente desse barulho normativo proveniente da temerária vigência do Anexo I da NR 15. Finalmente, este artigo suscita soluções que harmonizam os atos normativos interministeriais, ao tempo que propõe retificações de normas do INSS que desrespeitam mandamentos superiores.

Palavras-Chave: avaliação e tolerância aos ruídos; direitos trabalhistas; saúde do trabalhador.

ABSTRACT: This article approaches in a critical and propositive way the governmental inertia regarding the necessary harmonization of parameters, methodology, procedures and limits of tolerance pertinent to the noise risk factor. Within Brazil's federal government, there is an anomalous bifurcation from a legal-normative, as well as technical-procedural perspective regarding noise levels evaluation and tolerance, since what is valid for the Federal Revenue Service (Receita Federal do Brasil - RFB) and the National Institute of Social Insurance (Instituto Nacional do Seguro Social -INSS) does not apply to the Ministry of Labor (Ministério do Trabalho - MTb). Therefore, the right to a contribution time reduced to 25 years, granted by the INSS, and the corresponding payment by the company to the RFB, totalling $6 \%$ of the employee's remuneration, follow the Occupational Hygiene Standard 01 (Norma de Higiene Ocupacional NHO-01) published by Fundacentro (research institution linked to MTb), while the payment of additional remuneration by the company (20\% of the minimum wage) to its employees adopts the anachronistic, elusive and misguided Annex I of the Regulatory Standard 15 (NR15), published by MTb. This work contextualizes and explains the fiscal procedure and the recognition of rights attached to noise, through a historical, inclusive normative approach. The definition and meanings of the main evaluation parameters (Criterion Level - CL, Exchange Rate (ER) and Threshold Level - TL) are discussed. Practical examples that show the harmful consequences to the worker as a result of

Laborare. Ano I, Número 1, Julho/2018, pp. 85-117. ISSN 0000-0000. http://trabalhodigno.org/laborare 
this "normative noise", caused by the reckless validity of Annex I of NR 15, are presented. Finally, this article raises solutions that harmonize the normative interministerial acts, while proposing corrections of INSS norms that disobey superior commandments.

Keywords: assessment and tolerance for noise; labor rights; worker's health.

O presente artigo consiste em reunir e concatenar os atuais conhecimentos relacionados ao meio ambiente do trabalho com exposição ao fator de risco ruído, bem como a instrumentalizar a decisão daqueles obrigados a produzir, controlar, auditar, rastrear e transmitir informações relacionadas a esse fator de risco. Presta-se também, dada a premente necessidade, ao oferecimento de aporte material ao Manual do eSocial no tocante ao correto preenchimento do eSocial, de modo, nos termos da lei, assegurar às empresas segurança jurídica quanto aos fatos administrativos, contábeis e jurídicos; ao trabalhador, seus direitos; ao Instituto Nacional de Seguro Social - INSS o devido reconhecimento do direito previdenciário; ao Ministério do Trabalho - MTb, a fonte primária às obrigações trabalhistas; e, à Receita Federal do Brasil - RFB, a arrecadação, em especial aquela diretamente relacionada ao ruído, qual seja o Financiamento da Aposentadoria por Condições Especiais do Trabalho - FAE. Este ensaio foi estruturado com o intuito de unificação de entendimento que o tema enseja, a partir de um alicerce científico (físico e matemático), técnico e normativo contextualizado pela legislação de regência e suas origens nas normas de padronização internacional.

\section{ANTECEDENTES}

Informe-se antemão que o fator de risco ruído é de sobeja importância à saúde, dada sua etiogenia relacionada a diversos efeitos humanos, fartamente referenciados, em robusta bibliografia científica, da qual se destacam algumas consequências, em 
especial àquele que se subordina por força do contrato de trabalho à carga acústica ruidosa: reações físicas (aumento da pressão sanguínea, do ritmo cardíaco e das contrações musculares); aumento da produção de adrenalina e outros hormônios; reações mentais e emocionais (irritabilidade, ansiedade, impaciência, medo, insônia); reações generalizadas ao stress; e, efeitos deletérios auditivos ${ }^{1,2,3,4,5,6}$.

Não por outro motivo, encontra-se forte tutela estatal legiferante sobre essa temática, pois do ápice hierárquico até as normas referenciadas (instruções normativas e portarias), tem-se que a exposição ao ruído ativa vários campos do direito exatamente por sua natureza agressiva à saúde humana. Considerando a especificidade técnica da matéria em tela, faz-se a seguir um arrazoado para melhor situar o ruído na esfera do eSocial, e este, ao ordenamento jurídico que o vincula aos campos normativos previdenciários, trabalhistas e tributário. De pronto, é de bom alvitre registrar a fundamentação legal em questão com as seguintes normas de regência:

\section{Figura 1: Normas de Regência ao eSocial e aos Fatos Jurídicos \\ Decorrentes da Subordinação ao Ruído}

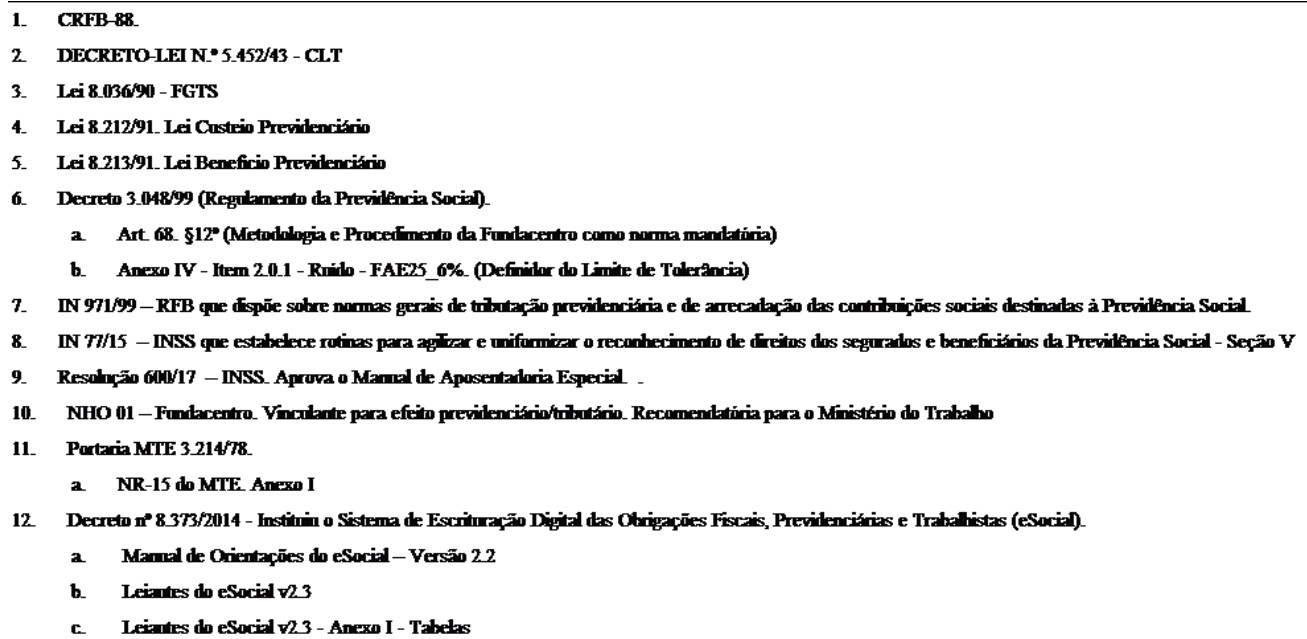

Fonte: Próprio Autor

Laborare. Ano I, Número 1, Julho/2018, pp. 85-117. ISSN 0000-0000. http://trabalhodigno.org/laborare 
Desse espectro normativo, se sobressaem os bens jurídicos tutelados: saúde do trabalhador; remuneração por adicionais; meio ambiente do trabalho; sustento quando da aposentadoria precoce por exposição intolerável e tributação correlata pela RFB, respectivamente com naturezas jurídicas sanitárias; trabalhistas; ambientais; previdenciárias e tributárias.

Além das repercussões difusas e coletivas, moduladas pelo direito ambiental e sanitário, que neste trabalho não serão abordadas, registre-se a importância do fato social - submeter trabalhador a risco (ruído)-, uma vez que ele dispara três consequências jurídicas específicas, divisíveis e individualizáveis por trabalhador, quais sejam: i) direito à redução no tempo de contribuição para 25 anos, inclusive com conversão, cujo reconhecimento se dá pelo INSS; ii) recolhimento pela empresa à RFB de 6\% da remuneração do trabalhador, sob fiscalização do Auditor-Fiscal da Receita Federal do Brasil - AFRFB do RFB; e, iii) pagamento de adicional de remuneração, pela empresa (20\% do salário mínimo) ao trabalhador, a título de insalubridade grau médio, sob fiscalização do AFT do MTb;

Adiante-se que, do ponto jurídico-normativo, bem como do técnico-procedimental de avaliação e tolerância ao ruído, apenas o adicional de insalubridade tem regra própria, exclusiva, que não intercepta aos regramentos do INSS e RFB, diga-se de passagem, anacrônica e obsoleta, como mais à frente se discute.

De forma vanguardista e em sintonia com os modernos cânones científicos, comparecem os regramentos estabelecidos pela RFB e INSS. Registre-se que as metodologias, procedimentos e limites de tolerâncias são rigorosamente os mesmos para fins tributários e previdenciários, pois emanam de igual regulamentação (Item 2.0.1 do Anexo IV do 
RPS), em que pese serem originárias de fundamentações legais distintas (Custeio pela Lei 8.212/91 e Benefício pela Lei 8.213/91) que remetem à subsunção de dupla face do fato social, constituindo uma ambivalência jurídica, pois tal fato social dispara a um só tempo a hipótese de incidência tributária (RFB) e reconhecimento ao benefício (INSS). A figura seguinte apresenta esse fragmento do RPS.

\section{Figura 2: Item 2.0.1 do Anexo IV e $\$ 12$ do Art. 68 com fragmentos do}

\section{Decreto 3.048/99}

\begin{tabular}{|c|c|c|c|}
\hline Limite de Tolerância & 20.1 & $\begin{array}{l}\text { Ruido a) exposiçäo a Niveis de Exposiçäo Nomalizados (NEN) } \\
\text { superiones a } 85 \mathrm{~dB}(\mathrm{~A}) \text {. }\end{array}$ & 25 Ancs \\
\hline \multirow{2}{*}{ Metrodologia e Procedimento } & \multicolumn{3}{|c|}{$\begin{array}{l}\text { RPS. Art 68. } \$ 12 \text { Nas avaliaçöes ambientais deveräo ser considerados, além do dispostó no } \\
\text { Anexo IV, a metodologia e os procedimentros de avaliaçäo estabelecidos pela Fundaçäo Jorge } \\
\text { Duprat Figueinedo de Segurança e Medicina do Trabalho - Fundacentro }\end{array}$} \\
\hline & \multicolumn{3}{|c|}{$\begin{array}{l}\text { A noma NHO } 01 \text { - Noma de Higiene Ocupacional da Fundacentro. Trata da metodologia e } \\
\text { procedimento para fins de apuraçäo do limite de trlerância ao nuido continuo ou vanível. }\end{array}$} \\
\hline
\end{tabular}

Fonte: próprio autor

O custeio se dá pela tributação relativa ao Financiamento da Aposentadoria por Condições Especiais do Trabalho - FAE, cujo fato gerador se consigna pela remuneração paga, devida ou creditada a trabalhador submetido a níveis de ruído contínuo ou variável, de modo permanente, que ultrapasse o Nível de Exposição Normalizado (NEN) de $85 \mathrm{~dB}(\mathrm{~A})$, conforme dispõe item 2.0.1 do Anexo IV do RPS (Limite de Tolerância), sendo tal avaliação apurada nos termos metodológicos e procedimentais definidos pela NHO-01 da Fundacentro (Metodologia e Procedimento), conforme dispõe o $\$ 12^{\circ}$ do Art. 68 do RPS. (Metodologia e Procedimento da Fundacentro como norma mandatória). 
Esse custeio - com natureza jurídica de taxa, dada a individualização, destinação específica e contrapartida vinculada - aponta para o sustento do benefício correspondente - Aposentadoria por Condições Especiais de Trabalho - ACET, que resulta em uma redução do tempo de contribuição por trabalhar subordinado às condições especiais prejudiciais à saúde e à integridade física. A ACET se dá segundo a mesma matriz de hipótese de incidência tributária, pois como vistos, comungam dos mesmos elementos essenciais à concretude do fator gerador. Depreendem-se, assim, os elementos essenciais dessa matriz ao FAE e, por conseguinte, à ACET, cujo público alvo legal são os segurados empregados, trabalhadores avulsos e contribuintes individuais (cooperado), quais sejam: i) remuneração; ii) pessoalidade; iii) subordinação jurídica; iv) nocividade; e, v) permanência.

O núcleo da hipótese de incidência tributária é composto por esses cinco requisitos cumulativos. Mira-se então no art. 57 da Lei no 8.213/91, cujo detalhamento normativo está articulado no RPS e nas instruções IN 971/2009 da RFB e IN 77/2015 do INSS. Mais especificamente no art. 292 da IN 971 da RFB. Percebe-se que há uma articulação entre as IN da RFB e do INSS, esta última como complemento à primeira. Diga-se de passagem, que a norma tributária, como campo autônomo do direito, poderia remeter a qualquer outra ou até ela mesma delimitar os critérios da hipótese de incidência. Preferiu-se, para assegurar eficiência normativa nacional, respaldada pela uniformização da legislação pela União Federal, substabelecer ao INSS tais critérios.

Assim, tem-se a diç̧ão da RFB, via IN 971, que vincula expressamente norma previdenciária à exação tributária do FAE.

Vê-se que a União Federal teve o cuidado de compatibilizar os textos infralegais de modo a preservar a funcionalidade a cada entidade, respeitando, porém, as respectivas competências. Destaca-se que de forma cruzada, há disposições sobre a mesma matéria

Laborare. Ano I, Número 1, Julho/2018, pp. 85-117. ISSN 0000-0000. http://trabalhodigno.org/laborare 
em ambas as dimensões (norma de benefício dispõe sobre custeio e vice-versa), tendo as duas IN (RFB e INSS) qualificado a subsunção de dupla face do fato social, constituindo uma ambivalência jurídica, pois tal fato social dispara a um só tempo a hipótese de incidência tributária (RFB) e reconhecimento ao benefício (INSS).

Isso se dá quando a norma da RFB remete a do INSS, e igualmente o INSS especifica e detalha, via Instrução Normativa INSS/PRES n ${ }^{\circ}$ 77, de 21/01/2015, em seu art. 278, os elementos que compõem o núcleo da hipótese de incidência tributária das contribuições previdenciárias que financiam o benefício da aposentadoria especial. Veja o que diz o citado dispositivo (grifado):

Art. 278. Para fins da análise de caracterização da atividade exercida em condições especiais por exposição à agente nocivo, consideram-se:

I - nocividade: situação combinada ou não de substâncias, energias e demais fatores de riscos reconhecidos, presentes no ambiente de trabalho, capazes de trazer ou ocasionar danos à saúde ou à integridade física do trabalhador;

II - permanência: trabalho não ocasional nem intermitente no qual a exposição do empregado, do trabalhador avulso ou do contribuinte individual cooperado ao agente nocivo seja indissociável da produção do bem ou da prestação do serviço, em decorrência da subordinação jurídica a qual se submete (...).

II - quantitativo, sendo a nocividade considerada pela ultrapassagem dos limites de tolerância ou doses, dispostos nos Anexos 1, 2, 3, 5, 8, 11 e 12 da NR-15 do MTE, por meio da mensuração da intensidade ou da concentração consideradas no tempo efetivo da exposição no ambiente de trabalho.

A despeito dessa dicção cruzada sobre o fato social gerador, tributário e previdenciário, nos campos dos respectivos direitos, remanesce a distinção do sujeito passivo das obrigações, uma vez que a normatização previdenciária as impõe ao segurado; 
enquanto a tributária, às empresas empregadoras desses mesmos segurados, pelo mesmo fato. O segurado faz prova mediante apresentação do Perfil Profissiográfico Previdenciário - PPP ao INSS; enquanto a empresa, via demonstrações ambientais apresentadas, por intimação, à autoridade competente (AFRFB).

Lembrando que a permanência está definida no art. 65 do Decreto 3.048/99. Explique-se, mais amiúde, que a exposição à nocividade ambiental somente será considerada permanente quando não houver grau de liberdade ao trabalhador a ela dizer não. Em outras palavras, o trabalhador para cumprir as determinações do empregador e prepostos (de produzir bens ou prestar serviços) - aos quais se submete por subordinação jurídica - tem que se expor aos fatores de risco prejudiciais à saúde ensejadores da aposentadoria especial. Das duas uma: ou descumpre ordem para não se expor e se sujeita a dispensa motivada por insubordinação ou cumpre ordem e se sujeita peremptoriamente à exposição agressora de sua saúde. A permanência tem a ver com inexistência de grau de liberdade à exposição.

Serão não permanente, não ocasional ou intermitente, todas as outras situações. O legislador não as definiu, também não precisava fazê-lo, pois são integrantes do conjunto complemento à definição que interessa, permanência, que está posta. $\mathrm{O}$ trabalho prestado pelo segurado (empregado, trabalhador avulso ou cooperado de cooperativa de trabalho ou de produção) é permanente quando a exposição aos agentes nocivos for inafastável e intrinsecamente vinculada ao desempenho das suas funções, independentemente do tempo e da frequência de exposição.

Importante modular que quando o trabalhador está na base da pirâmide hierárquica fica clara e inescusável a permanência, todavia à medida que se sobe na pirâmide, exige-se da empresa maior cuidado na descrição da ordem de serviço, pois há 
necessidade de discriminar o grau de liberdade à exposição, dentro das possibilidades desse trabalhador se afastar da fonte geradora, no âmbito do limite de competência.

\section{RUÍDO: PROCEDIMENTO FISCAL E RECONHECIMENTO DE DIREITOS}

É importante destacar a natureza jurídica das normas em questão, interpretando-as sistemática e teleologicamente ante os bens jurídicos tutelados: saúde do trabalhador; remuneração por adicionais; meio ambiente do trabalho; manutenção do poder aquisitivo quando da aposentadoria precoce por exposição intolerável e tributação correlata (FAE), respectivamente com naturezas jurídicas sanitárias, trabalhistas, ambientais, previdenciárias e tributárias.

Não obstante as múltiplas ativações normativas na matéria em tela, há que se enfatizar a soberania das imposições tributárias perante as demais, quando se tratar de contribuição previdenciária, espécie de tributo, por força de norma tributária, ainda que esta referencie aquelas. Não obstante, para fỉns de constituição do crédito tributário não há qualquer interferência, sobreposição, dúvida e, nem de longe, conflito normativo, nem mesmo aparente, com quaisquer normas. Isso porque o comando acima é cristalino e direto: fato gerador se consigna pela remuneração, paga, devida ou creditada, a trabalhador submetido a níveis de ruído contínuo, ou variável, de modo permanente, que ultrapasse o Nível de Exposição Normalizado (NEN) de $85 \mathrm{~dB}(\mathrm{~A})$, conforme dispõe item 2.0.1 do Anexo IV do RPS (Limite de Tolerância), sendo tal avaliação apurada nos termos metodológicos e procedimentais definidos pela NHO 01 da Fundacentro (Metodologia e Procedimento), conforme dispõe o $\$ 12^{\circ}$ do Art. 68 do RPS. (Metodologia e Procedimento da Fundacentro como norma mandatória).

Laborare. Ano I, Número 1, Julho/2018, pp. 85-117. ISSN 0000-0000. http://trabalhodigno.org/laborare 
Essa disposição de limite de tolerância (NEN de $85 \mathrm{~dB}(\mathrm{~A})$ ou dose unitária) foi inaugurada no Brasil pelo Decreto 4.882, de 28 de novembro de 2003, que alterou o Regulamento da Previdência Social. Nesta oportunidade, ao estabelecer o NEN, ela automaticamente se reporta à NHO 01 da Fundacentro, uma vez que o conceito de "Nível Exposição Normalizado" não existe além desse mandamento na legislação pátria, indicando que a referida norma deve ser utilizada inclusive como parâmetro de limite de exposição para ruído. Isso implica um fator de incremento de dose igual a três $(q=3)$ e todas as consequências inerentes a essa alteração, impactando a legislação tributária e previdenciária, ao tempo que força modificação e atualização dos limites da legislação trabalhista.

A RFB está vinculada a um procedimento fiscal que, neste caso, independe de normas trabalhistas, dado o comando expresso e peremptoriamente declarado pelo item 2.0.1 do Anexo IV do RPS (Limite de Tolerância - LT) ao determinar que o LT é 85 dB(A), aferido em Nível de Exposição Normalizado (NEN), cuja metodologia e procedimento devem se ater à NHO 01 da Fundacentro. Ou seja, o Decreto 3.048/99 expressou, em termos materiais e procedimentais, tudo que se necessita para formatar a matriz tributária ao enumerar todos os elementos, intrínsecos e extrínsecos, do fato gerador.

Desta feita, não há o que se cogitar sobre conflito com norma trabalhista, especificamente com Anexo I da NR 15 - como se houvesse, pois, conflito não há, como se verá à frente - pelo simples fato de essa dita norma não constar da matriz de incidência acima. Frise-se que não há interseção com a norma trabalhista (Anexo I da NR 15). Por pura ilação jurídica, se fosse possível aceitar o absurdo principiológico segundo o qual havendo conflito entre normas de hierarquia distinta, sobre a mesma matéria, uma norma de menor hierarquia (IN 77/15 do INSS) pudesse sobrepor a uma superior (Decreto Regulamentador), ainda assim tal conflito não existiria, dado que, segundo o que dispõe a IN 77, ter-se-ia Laborare. Ano I, Número 1, Julho/2018, pp. 85-117. ISSN 0000-0000. http://trabalhodigno.org/laborare 
convergência das consequências técnicas, práticas e jurídicas, levando ao mesmo resultado. O art. 280 da IN 77 do INSS, dispõe:

Art. 280 - A exposição ocupacional a ruído dará ensejo a caracterização de atividade exercida em condições especiais quando os níveis de pressão sonora estiverem acima de oitenta $\mathrm{dB}(\mathrm{A})$, noventa dB (A) ou 85 (oitenta e cinco) dB (A), conforme o caso, observado o seguinte:(...) IV - a partir de 01 de janeiro de 2004, será efetuado o enquadramento quando o Nível de Exposição Normalizado - NEN se situar acima de 85 (oitenta e cinco) dB (A) ou for ultrapassada a dose unitária, conforme NHO 1 da Fundacentro, sendo facultado à empresa a sua utilização a partir de 19 de novembro de 2003, data da publicação do Decreto ${ }^{\circ}$ 4.882, de 2003, aplicando:

a) os limites de tolerância definidos no Quadro do Anexo I da NR15 do MTE; $\mathrm{e}$

b) as metodologias e os procedimentos definidos nas NHO-01 da Fundacentro.

Depreende-se do dispositivo acima que a IN 77/15 se alinhou ao decreto ao se submeter ao mesmo Limite de Tolerância $(\mathrm{LT}=\mathrm{NEN}=85 \mathrm{~dB}(\mathrm{~A})$ ), que implica dose unitária $(100 \%)$, bem como delineou metodologias e os procedimentos iguais ao decreto. Ou seja, o caput, e na alínea "b", respeitou a hierarquia das normas; todavia, na alínea "a" descarrilou criando o imbróglio.

Isso porque a alínea "a" aponta para outro LT (aqueles do Anexo I da NR-15 do MTE), se insubordinando ao já estabelecido no caput ( $L T=N E N=85 \mathrm{~dB}(\mathrm{~A})$. Pode a alínea circunscrever o conteúdo e alcance do caput; jamais, desdizê-lo. Foi exatamente isso que fez a alínea "a" do art. 280 da IN 77 do INSS. O caput diz que o LT é NEN de $85 \mathrm{~dB}(\mathrm{~A})$, enquanto a alínea "a" estabelece que o LT são aqueles do Anexo I da NR 15 do MTE.

Laborare. Ano I, Número 1, Julho/2018, pp. 85-117. ISSN 0000-0000. http://trabalhodigno.org/laborare 
Portanto, quando duas normas de hierarquias distintas dispõem sobre a mesma matéria, prevalece aquela de grau superior, no caso o decreto. Logo, a alínea "a" da IN 77 do INSS é letra morta. O Anexo I da NR-15 do MTE não compõe a matriz do fato gerador. É algo estranho, inócuo, impertinente, incompatível, despiciendo e obviamente antijurídico. Não deve produzir efeitos, muito menos comparecer nos autos. Procedimento crítico que materializa o equívoco, potencializando-o, diz respeito ao Manual de Perícia do INSS que segue essa alínea "a", por motivos idênticos, exigindo fator de troca $\mathrm{q}=5$ ao arrepio do Decreto 3.048/99.

Em resumo, a RFB deve constituir o crédito tributário, qualquer que seja das duas interpretações: i) aplicando NEN e metodologia e procedimentos diretamente da NHO 01 da Fundacentro, descartando integralmente o Anexo I da NR 15, que é o entendimento correto; ii) ou, conhecendo do Anexo I da NR 15 apenas, e unicamente, o seu item 6, descartando tudo mais (tabela, seus limites e o fator de dobra ( $q=5$ ), bem como a metodologia e procedimentos), conquanto se reafirme prejudicado tal entendimento pelos motivos já explanados.

Dessa forma, cabe ao AFRFB perscrutar e perquirir, mediante papéis de trabalho, se há ou não concretude da hipótese de incidência segundo a hierarquia: Lei 8.212/91 e Lei 8.213/91; Decreto 3048/99 e finalmente NHO 01 da Fundacentro. Devendo o AFRFB constituir o crédito tributário, nos termos da IN 971 da RFB, por arbitramento, quando verificar o não atendimento da obrigação acessória relativa às formalidades do LTCAT, ou seu substituto, o PPRA, no tocante ao cumprimento (check-list) do método e procedimento definidos pela NHO 01 da Fundacentro.

Há um facilitador à gestão ambiental das empresas, às regras de concessão de benefício pelo INSS e à fiscalização da RFB, pois é desnecessário checar dados sobre Equipamento de Proteção Individual - EPI, uma vez que tais equipamentos são 
absolutamente ineficazes. O Supremo Tribunal Federal (STF) concluiu dia 04/12/2014, em julgamento do Recurso Extraordinário com Agravo (ARE) 664335, com repercussão geral reconhecida, e fixou duas teses que são aplicadas em todo o país sobre os efeitos da utilização de EPI sobre o direito à aposentadoria especial.

Para embaraçar ainda mais, comparece o 2.6.3.1 do Manual de Perícia Médica aprovado pela Resolução 600 do INSS, de 10/08/2017, ao repetir o vício já apontado insistindo na antijurídica alínea "a" da IN 77 do INSS. Todavia vai além, ao ponto de determinar uma fórmula diferente daquela expressa pela NHO 01 apenas para acomodar o erro do fator de troca $\mathrm{q}=5$, repita-se, ao arrepio do item 2.0.1 do Anexo IV do Decreto 3.048/99.

Este Manual do INSS, ainda que mencione a fórmula do NEN da NHO 01, qual seja, $\mathrm{NEN}=\mathrm{NE}+10 \log \left(\frac{\mathrm{Te}}{100}\right)[\mathrm{dB}]$, solenemente ignora a hierarquia das normas e ao invés de explicá-la, a deturpa, introduzindo, de forma dissimulada, uma constante 16,61. Observe-se que o fator "q", não consta da fórmula, mas foi considerado na constante numérica 16,61, uma vez que a mesma é obtida da primeira parcela da equação do NEN: $\frac{q}{\log 2}$.

Assim aplicando $\mathrm{q}=5$, tem-se $\left(\frac{\mathrm{q}}{\mathrm{Log} 2}=\frac{5}{\log 2}\right)$ que resulta na constante 16,61. Na prática, serve para considerar o q=5 em nova ofensa ao Decreto 3048, conforme a seguir se transcreve, in verbis, da página 88 daquele manual (grifado): “Como a metodologia da Fundacentro prevê para o cálculo do $N E$ o $Q=3$, caso a aferição tenha por referência $Q=5$, aplica-se para o cálculo do NEN, a seguinte fórmula adaptada: $N E N=N E+\underline{\mathbf{1 6 , 6 1}} \times 10 \log T E / 480[\mathrm{~dB}]^{\prime \prime}$. 
Nesse Manual, no tocante ao ruído, há várias remissões antijurídicas ao Anexo I da NR 15, por se confrontarem com norma de hierarquia superior e devem ser consideradas nulas. Registre-se que, por esse motivo, todas as referências desse Manual ao Fator de Dobra q=5 e Nível limiar de integração $=85 \mathrm{~dB}(\mathrm{~A})$, bem como ao Anexo I da NR 15, como todo, devem ser desconsideradas.

Finalmente, sem qualquer sombreamento de dúvida, consagram-se os requisitos moldadores do fato gerador da aposentadoria por condições especiais consubstanciados no limite de tolerância do $\mathrm{NEN}=85 \mathrm{~dB}(\mathrm{~A})$, que implica dose de unitária (100\%), apresentados em PPP e apurados mediante LTCAT compatível com as competências auditadas, segundo as metodologias e os procedimentos definidos nas NHO-01 da Fundacentro. Em outras palavras, cabe única e exclusivamente adotar os parâmetros de medição estabelecidos pelo Decreto 3.048/99, instrumentalizados pela norma NHO 01 da Fundacentro, que serve ao reconhecendo do direito pelo INSS e ao crédito tributário pela RFB, considerando obrigatoriamente o Nível limiar de integração $=80 \mathrm{~dB}(\mathrm{~A})$ e Incremento de duplicação de dose $=3(\mathrm{q}=3)$

\section{APLICAÇÕES CONFORME NORMAS PREVIDENCIÁRIAS, TRIBUTÁRIAS E TRABALHISTAS}

Para fins dos regramentos do INSS e RFB, que comandam a NHO 01 da Fundacentro como norma mandatória, a avaliação da exposição ocupacional ao ruído contínuo ou intermitente deverá ser feita por meio da determinação da dose diária de ruído (D) ou do nível de exposição (NE), parâmetros representativos da exposição diária do trabalhador. Esses parâmetros são totalmente equivalentes, sendo, possível, a partir de um obter-se o outro, mediante as expressões matemáticas dispostas nessa norma. 
Se o NEN for superior a $85 \mathrm{~dB}(\mathrm{~A})$, tem-se o reconhecimento da aposentadoria especial pelo INSS ao mesmo tempo que dispara a constituição do crédito tributário consonante à rubrica FAE. Esse reconhecimento de face dupla se dá pela empresa via GFIP/eSocial ao consignar nos campos próprios, para cada mês-competência e por NIT, os códigos de 25 anos e alíquotas de $6 \%$.

A empresa não declarando em GFIP/eSocial tal fato social (NEN for superior a 85 $\mathrm{dB}(\mathrm{A})$ ), obriga ao AFRFB constituir crédito tributário correlato, por arbitramento, nos termos da IN 971/15 da RFB, obrigando por via direta ao INSS reconhecer o direito à conversão em especial do período autuado. Superado esse primeiro estofo conceitual sobre o fator ruído perante disposições do INSS e RFB, apresentam-se a seguir algumas considerações basilares ao terceiro efeito: adicional de insalubridade regulado pelo Anexo I da NR 15 do MTb.

\section{Adicional de Insalubridade}

O Anexo I da NR 15 serve, apenas, e tão somente, para pagar adicional de insalubridade. O Anexo IV do RPS vincula norma NHO 01 da Fundacentro, logo o Anexo I da NR 15 não se aplica à matriz tributária do FAE. Reforce-se que os critérios para constituição do crédito tributário do FAE, bem como para concessão de aposentadoria especial estão lá devidamente pavimentados. Todavia, por conta da intromissão interpretativa que o Anexo I da NR 15 provoca, faz-se necessário pacificar sobre o suporte científico e a interferência política dessa norma de compensação monetária ao risco deliberado mediante pagamento de $20 \%$ do saláriomínimo. Pacificar a matéria quer dizer: evitar escapismos semânticos e ginásticas hermenêuticas que suscitam teses mirabolantes nos tribunais tendentes a inviabilizar o reconhecimento de direito pelo INSS e à sonegação fiscal, escamoteadas por uma norma trabalhista obsoleta, anacrônica e matematicamente errada.

Laborare. Ano I, Número 1, Julho/2018, pp. 85-117. ISSN 0000-0000. http://trabalhodigno.org/laborare 
O erro se explica. $O$ logaritmo de 2 na base 10 é igual a 0,3010 que vezes 10 , para reverter o deci da unidade $\mathrm{dB}$ perfaz, aproximadamente 3 . Ou seja, se se deseja descobrir o dobro da intensidade em $\mathrm{dB}$, e a função de audibilidade (Pressão - Pa versus frequência - Hz) varia segundo uma curva logarítmica, tem-se que é necessário operar o $\log$ de 2 representante do fator de dobra 3 ( $q=3$ ).

A Portaria 3.214 do MTE, no original, com 28 Normas Regulamentadoras - NR (hoje com 36), foi publicada em $1978^{2}$. Nesse bojo, veio o Anexo I da NR 15 que trata de ruído, conjuntamente aos demais anexos, mantendo-se intacto desde então, em que pesem as brutais transformações tecnológicas, científicas e sociais nesses 40 anos, notadamente a Promulgação da Constituição Federal de 1988. Essa portaria regulamentou o Capítulo V da CLT, que passou a tratar da matéria de forma sistêmica e ampliada, no campo do direito trabalhista, por força da recém-editada Lei 6.514 de 1977. Dadas as condições prementes à época, a comissão (MTE e Fundacentro) encarregada da regulamentação dessa lei teve por bem "importar" o estado da arte estadunidense, traduzindo para o Brasil as normas da American Conference of Governmental Industrial Hygiene - $\mathrm{ACGIH}^{8}$ em vigor em 1976. Portanto, ainda se aplica no Brasil de hoje uma definição de insalubridade dos EUA daquela época.

Nesse mister, discorre-se sobre dois pilares que sustentam o diagnóstico e suas consequências: o ambiente do trabalho está ou não com nível sonoro além do que se permite à saúde humana? Esses pilares são: Critério de Referência e Fator de Dobra. Critério de Referência (CR), conforme ISSO 1999/90ㄹ, é o corte populacional (quantum de sacrifício) que admite uma parcela de $50 \%$ da população exposta a um ambiente ruidoso venha a desenvolver perda auditiva superior a: $2 \mathrm{~dB}$, na média, para

${ }^{2}$ Os TLV ${ }^{\circledR}$ utilizados como referência pela legislação brasileira, eram da ACGIH ${ }^{\circledR}, 1976$. Os TLVs $A C G I H{ }^{\circledR}$ levavam em conta a jornada de trabalho de 40 horas/semana. No Brasil, foram ajustados para 48 horas/semana e passaram a ser $22 \%$ menores do que os valores da ACGIH.

Laborare. Ano I, Número 1, Julho/2018, pp. 85-117. ISSN 0000-0000. http://trabalhodigno.org/laborare 
frequências de 0,5, 1, 2 e $3 \mathrm{KHz}$ respectivamente, para 40 anos de exposição; 1,5 dB, na média, para frequências de 0,5,1,2 e $3 \mathrm{KHz}$ respectivamente, para 20 anos de exposição; e $1 \mathrm{~dB}$, na média, para frequências de $0,5,1,2$ e $3 \mathrm{KHz}$ respectivamente, para 10 anos de exposição.

Atualmente, no Brasil, há unificação de CR e ambas as normas (Anexo I da NR 15 e NHO 01 da Fundacentro) alinhada à norma padrão internacional ISO 1999/90 que corresponde: a um nível médio, $85 \mathrm{~dB}(A)$, para o qual a exposição, por um período de 8 horas, corresponderá a uma dose de 100\%. Portanto, não há controvérsia nesse quesito.

Está no quesito Fator de Dobra a cizânia e motivo de tanta polêmica: situação esdrúxula. O Brasil convive com dois fatores: um anacrônico e obsoleto ( $\mathrm{q}=5$ ) segundo o Anexo I da NR 15; outro, compatível com as evidências científicas mais robustas (q=3) da NHO 01 da Fundacentro.

Para conduzir a explicação, faz-se a pergunta: por que o Anexo I da NR-15 do MTE destoa da metodologia, procedimento e limites da NHO 01 da Fundacentro? Qual é a origem dessa controvérsia? Respostas: basicamente porque o Anexo I da NR-15 do MTE está obsoleto e anacrônico. Carece de atualização. Esse Anexo I representa o estado da arte existente na ciência na década de 70 do século passado, quando a edição da ACGIH serviu de base à Portaria 3.214/78 do MTE que aprovou as Normas Regulamentadoras - NR, e dentre elas a NR $15^{10}$.

Enquanto que as normas da Fundacentro, por não dependerem e nem conterem as amarras do tripartimo, e, portanto, menos sujeitas aos interesses empresariais, conseguem seguir uma trajetória de atualização compatível aos avanços das ciências e necessidades sociais, a NHO 01, por exemplo, foi editada e produz efeitos desde o ano de 2001.

Laborare. Ano I, Número 1, Julho/2018, pp. 85-117. ISSN 0000-0000. http://trabalhodigno.org/laborare 
Os valores dos limites de tolerância da Portaria 3.214/78 foram estabelecidos com base na ACGIH-1976, que é uma entidade internacional dedicada ao estudo e à proposição de limites para os vários agentes ambientais, os chamados Thresold Limit Value - TLV® (Limites de exposição). Os TLV® são níveis ou concentrações a que se acredita que a maioria dos trabalhadores possa estar exposta, dia após dia, sem sofrer efeitos adversos à saúde (ACGIH, 1958) ${ }^{11}$.

A diferença entre a definição técnica dos TLV e a definição legal dos LT é que a lei não pode fazer distinção entre pessoas, de modo que os LT se aplicam igualmente a todos os trabalhadores asseverando que abaixo dele todos estão protegidos. Por outro lado, a definição técnica (TLV) não é tão rígida, permitindo que os limites de exposição não sejam aplicados a todos os trabalhadores, devido à variação da susceptibilidade individual, em que uma parcela poderá apresentar até uma determinada doença em concentrações iguais ou inferiores ao $\mathrm{LT}^{12}$.

Segundo a Figura 3 da TLV® da ACGIH de 1976, com adaptações, ao Anexo I da NR - 15 da Portaria 3.214/78, a exposição diária pode ser apresentada em decibéis ou em porcentagem, sendo que se tem como critério de referência (CR), para a jornada de um dia de trabalho, a exposição de 8 horas a $85 \mathrm{~dB}(\mathrm{~A})$, o que corresponde a uma dose de exposição de $100 \%$. Se a dose exceder $100 \%$, será ultrapassado o limite de exposição permitido.

\section{Figura 3: Fonte primária do Anexo I da NR - 15 da Portaria 3214/78 (transcrição do original)}




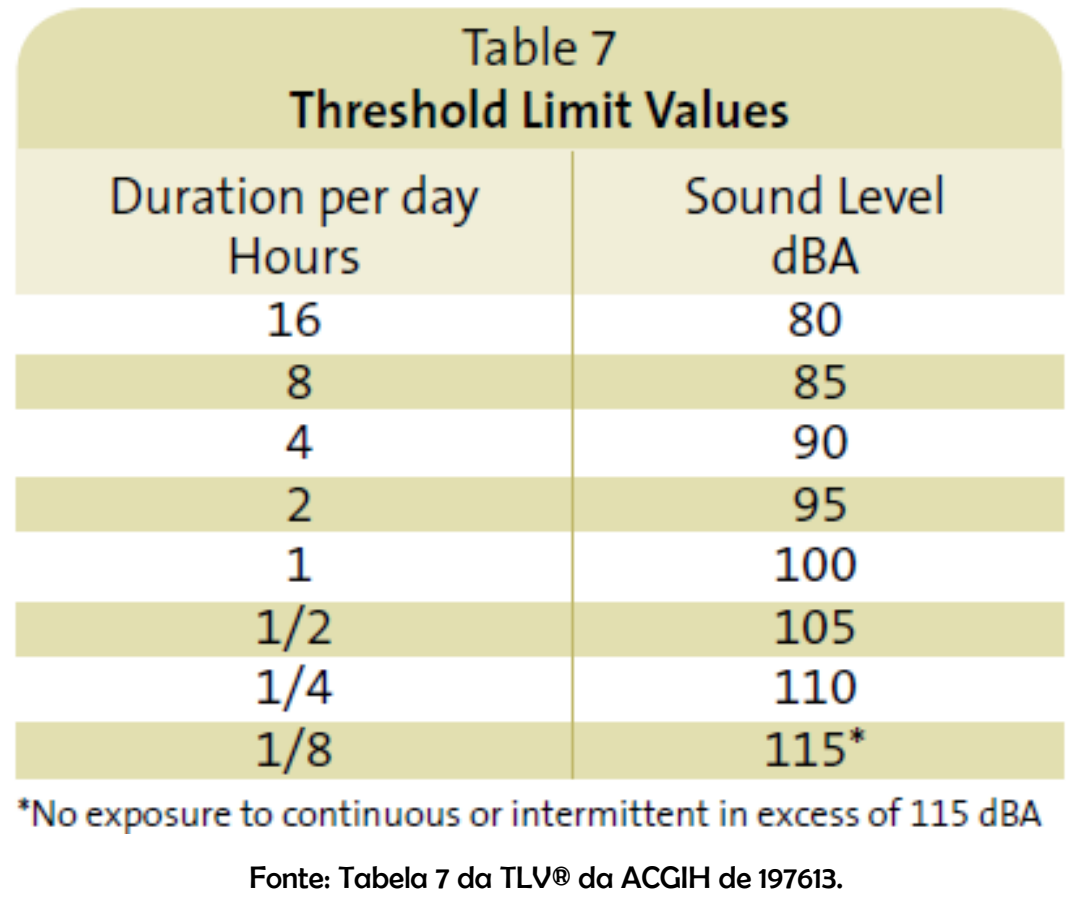

A versão brasileira dessa tabela foi adaptada ao Anexo I da NR - 15 inserindo mais linhas acima $85 \mathrm{~dB}(\mathrm{~A})$ e suprimindo todas as linhas abaixo disso. $\mathrm{O}$ acréscimo de linha para intensidade sonora superior a $85 \mathrm{~dB}(\mathrm{~A})$ foi dado pela fórmula: $\mathrm{T}(\mathrm{h})=\frac{16}{2^{\frac{\operatorname{Lavg} g-80}{5}}}$

Assim, se preencheu o Anexo I da NR - 15, versão brasileira da Tabela 7 - TLV® da ACGIH de 1976. Diz-se adaptada porque a versão brasileira fez inserção de linhas para intensidades acima $85 \mathrm{~dB}(\mathrm{~A})$ e supressão daquelas abaixo disso inexistente nos originais estadunidenses. A figura a seguir apresenta a tabela inteira aplicando a fórmula e comparando ao que está legislado. Depreendem-se do Anexo I da NR 15 que os seguintes parâmetros Nível limiar de integração $=85 \mathrm{~dB}(\mathrm{~A})$ e Incremento de duplicação de dose $q=5$ estão equivocados. 
Além da estagnação do Anexo I da NR - 15 às práticas e saberes da ACGIH do ano de 1976, há um enorme agravante, pois, a importação que foi feita em 1978, ao se publicar a Portaria 3.214/78, trouxe consigo vieses introduzidos por força de compatibilização normativa, conforme se aponta a seguir.

A tabela original indicava Nível Limiar de Integração $=80 \mathrm{~dB}(\mathrm{~A})$, que correspondia a 16h de jornada (no máximo). Os técnicos da Fundacentro sinalizaram com o aceite desse limite, todavia o setor jurídico do MTE não acatou a recepção dessas linhas da tabela argumentando que a carga horária máxima permitida era de $8 \mathrm{~h}$ e não faria sentido previsão de limites para tempos superiores. Dessa forma, os tempos máximos permitidos para exposição superiores a $80 \mathrm{~dB}(\mathrm{~A})$ e inferiores a $85 \mathrm{~dB}(\mathrm{~A})$ foram simplesmente excluídos da importação. Essa exclusão implica resultados siginificatimente inferiores aos que seriam obtidos caso computadas as exposições a partir de $80 \mathrm{dBA}$.

$\mathrm{Na}$ versão original, constava a somatória de frações de dose, cujo método é a dosimetria. Por que então isso não ficou expresso na Portaria? O dosímetro, à época, era raridade aqui no Brasil. As empresas e a fiscalização deveriam tê-lo, todavia o próprio governo não dispunha. Daí a simplificação para uso medidor de pressão sonora instantânea, cujo nível de erro é altíssimo. Tanto é que a própria NHO 01 da Fundacentro o proíbe nas situações acústicas de variação e multiplicidade altas.

Consequência prática do descarte dos tempos máximos permitidos para exposição inferiores a $85 \mathrm{~dB}(\mathrm{~A})$ e superiores a $80 \mathrm{~dB}(\mathrm{~A})$, bem como do uso de $\mathrm{q}=5$, aparece com as horas-extras, prática muito comum. Assim, para 12h de trabalho, tem-se um nível sonoro médio de $\mathrm{L}_{\mathrm{avg}}=82 \mathrm{~dB}(\mathrm{~A})$. Como essa energia está entre $85 \mathrm{~dB}(\mathrm{~A})$ e 80 dB(A), deve ser descartada. Há aqui flagrante ofensa ao trabalhador, com agravante de inclusive dissimular o pagamento do adicional e consigo o direito a se aposentar mais cedo. Ademais, ataca-se o princípio constitucional da dignidade da pessoa 
humana, comete-se crime de sonegação fiscal por deixar recolher FAE à RFB, bem como o direito à redução de risco.

Esse fato se agrava mesmo quando se mantém o Lavg em $85 \mathrm{~dB}(\mathrm{~A})$, pois, novamente, basta fazer hora-extra, além das $8 \mathrm{~h}$, para se agredir o trabalhador sem a subsunção do adicional de insalubridade, conforme se demonstra a seguir: $\mathrm{T}(\min )=\frac{16}{2 \frac{85-80}{5}}=8 \mathrm{~h}$

Ou seja, pela fórmula acima, qualquer quantidade de tempo extra a $85 \mathrm{~dB}(\mathrm{~A})$, depois das $8 \mathrm{~h}$ nessa condição, ultrapassa-se a dose de $100 \%$. A desvantagem ao trabalhador se agrava, notadamente nesse intervalo entre $85 \mathrm{~dB}(\mathrm{~A})$ e $80 \mathrm{~dB}(\mathrm{~A})$.

\section{Figura 4: Carga ruidosa descartada para fins de pagamento de horas- extras ou quando se expõe a menos de $85 \mathrm{~dB}(\mathrm{~A})$}

\begin{tabular}{|r|l|}
\hline $\begin{array}{c}\text { Nivel de nido } \\
\text { dB (A) }\end{array}$ & $\begin{array}{c}\text { Máxima } \\
\text { exposiçäo diánia }\end{array}$ \\
\hline 80 & 16 horas \\
\hline $\mathbf{8 1}$ & $\mathbf{1 4}$ horas \\
\hline $\mathbf{8 2}$ & $\mathbf{1 2}$ horas \\
\hline $\mathbf{8 3}$ & $\mathbf{1 0}$ horas \\
\hline 84 & 09 horas \\
85 & 08 horas \\
\hline
\end{tabular}

Fonte: próprio autor

Por tudo isso, reforça-se a bifurcação necessária quanto à exegese normativa, pois quando o objeto for pagamento de adicional de insalubridade por ruído contínuo ou intermitente deve se aplicar o Anexo I da NR 15. Apenas para esse fim. Para os demais propósitos (RFB; INSS; prevenção do meio ambiente do trabalho e poluição ambiental em relação aos trabalhadores, bem como para pesquisa e desenvolvimento científico em todas as áreas relacionadas à saúde humana), a NHO 01 da Fundacentro 
é mandatória, por força do direito, quando norma superior a vincula, tal qual o caso da RFB e INSS, assim como pela verdade científica, dado que hoje seus procedimentos e metodologias se coadunam aos conhecimentos vigentes, coisa que definitivamente o Anexo I da NR 15 se distanciou há muito.

A figura seguinte apresenta a evolução dos parâmetros e demonstra o quão equivocada se encontra a norma trabalhista brasileira para fins de insalubridade perante demais referências e até mesmo o desprestígio à produção científica da Fundacentro, ainda, e talvez por isso, vinculada ao MTb. Com destaque para ACGIH, precursora do Anexo I da NR 15, que nas edições subsequentes reconheceu e atualizou seus parâmetros.

Figura 5: Referências normativas e seus parâmetros para avaliação de ruído ${ }^{14}$

\begin{tabular}{|c|c|c|c|c|c|c|}
\hline Paranetion & ACGNH(19\%) & $\begin{array}{c}\text { Anexol d } 1 \mathrm{Rm} 15 \\
(197)\end{array}$ & $\begin{array}{l}\text { No01d } \\
\text { Fundacentio } \\
\text { (2001) }\end{array}$ & ACGM(2017) & OSHA(2017) & babetrss \\
\hline $\begin{array}{l}\text { Critiétio de } \\
\text { Peferência }\end{array}$ & $\begin{array}{c}\text { Dose } 100 \% 8 h \\
\text { por dia } 85 \mathrm{~dB} \text { (A) }\end{array}$ & $\begin{array}{c}\text { Dose } 100 \% 8 h \\
\text { por dia } 85 \text { dB (A) }\end{array}$ & $\begin{array}{c}\text { Dose 100\% } 8 \text { h } \\
\text { por dia } 85 \text { dB (A) }\end{array}$ & $\begin{array}{c}\text { Dose 100\% } 8 \text { h } \\
\text { por dia } 85 \mathrm{~dB} \text { (A) }\end{array}$ & $\begin{array}{c}\text { Dose 100\% } 8 \text { h } \\
\text { por dia 90dB (A) }\end{array}$ & \multirow{3}{*}{ NHOO } \\
\hline $\begin{array}{c}\text { Fafor de } \\
\text { Troca qa } \\
\text { (d?:A) }\end{array}$ & 5 & 5 & 3 & 3 & 5 & \\
\hline 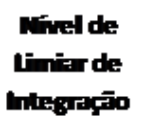 & $85 \mathrm{~dB}(\mathrm{~A})$ & $85 \mathrm{~dB}(\mathrm{~A})$ & $85 \mathrm{~dB}(\mathrm{~A})$ & $85 \mathrm{~dB}(\mathrm{~A})$ & $90 d B(A)$ & \\
\hline
\end{tabular}

Fonte: Próprio Autor

Destaque-se que a Presidência da República, mediante decreto, vinculou e deu caráter cogente às normas da Fundacentro quando se tratar de direito previdenciário e tributário. Todavia, remanescem tais normas como recomendatórias no campo do MTb. 
Para se ter uma ideia prática do enorme prejuízo à saúde do trabalhador que a manutenção desse Anexo I da NR 15 provoca, faz-se uso, a seguir, do estudo das pesquisadoras da Fundacentro - Teresa Cristina Nathan Outeiro Pinto e Maria Cristina Esposito Silverio - que, mediante exemplificação de campo, deixa insofismável tal assertiva ${ }^{15}$. Têm-se cinco trabalhadores de uma usina de reciclagem de entulho da construção civil, conforme quadro:

\begin{tabular}{lc}
\multicolumn{1}{c}{ Cago } & Trubethedor \\
\hline Operador de botoeira & A \\
Separador na esteira proximo ao britador & B \\
Motorista da pá carregadeira & C \\
Separador de material na frente da esteira & D \\
Ajudante na separaçāo de material & E \\
\hline
\end{tabular}

Fonte: Teresa e Maria Cristina (2005)

A avaliação ambiental foi realizada com dosímetros de ruído que permitiam a colocação dos dois critérios de referência: Anexo 1 da NR 15 e da NHO 01 (Fundacentro). Como os parâmetros utilizados eram diferentes, as doses de exposição obtidas também foram diferenciadas, conforme demonstrado.

Figura 6: Resultados obtidos avaliação cinco trabalhadores de uma usina de reciclagem de entulho da construção civil 


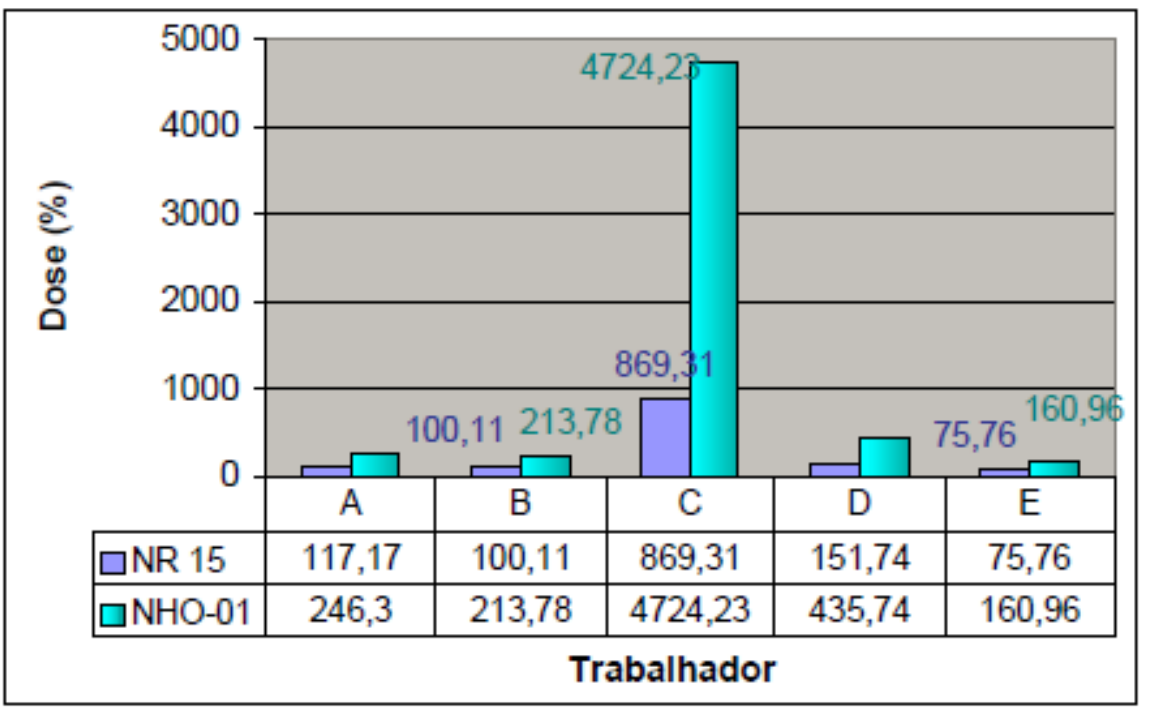

Fonte: Revista ABHO, v. 9, n. 21, set./2010.

A análise dos dados permite concluir que os cinco trabalhadores estão em situação de risco pelo critério da NHO 01; porém, o "E”, não, dada a permissividade da NR 15, que aponta dose de 75,76\%. Para os cinco trabalhadores há ativação do tributo FAE e, portanto, obrigação da empresa em recolher à RFB a quantia de 6\% sobre as remunerações, tendo os mesmos direitos à conversão de tempo para especial (25 anos), nesse mês de trabalho declarado em GFIP (eSocial).

O disparate se acentua quando se verifica que a empresa deixará de pagar adicional de insalubridade ao trabalhador "E", pois, pela NR 15, a dose ficou abaixo de $100 \%$ $(75,76 \%)$, apesar da energia real, verdadeira, ser de 2,12 vezes maior e ultrapassar em 60,96\% o máximo permitido. Ou seja, ativou norma tributária e previdenciária, isentando de alcance a trabalhista.

Detalhe marcante são as diferenças de magnitude das doses comparadas, cujas razões entre NHO 01 (valor verdadeiro) e NR 15 (valor comprimido) mostram, respectivamente: 2,10 para "A"; 2,13 para "B"; 5,43 para "C"; 2,87 para "d" e 2,12 para "E". 
Esse exemplo prático das pesquisadoras demonstra de forma cabal o enorme prejuízo à verdade científica e ao direito do trabalhador, com todas consequências ambientais, previdenciárias, sanitárias e tributárias, sem falar é claro do mais importante: o ultraje à dignidade da pessoa humana. Há nesse exemplo algumas explicações que maculam a aplicação do Anexo I da NR 15:

- Descarte das energias inferiores a $85 \mathrm{~dB}(\mathrm{~A})$ e superiores a $80 \mathrm{~dB}(\mathrm{~A})$, por conta da parametrização de Nível de Limiar de Integração - NLI em 85 dB(A), na jornada normal.

- Descarte das energias inferiores a $85 \mathrm{~dB}(\mathrm{~A})$ e superiores a $80 \mathrm{~dB}(\mathrm{~A})$, por conta da parametrização de Nível de Limiar de Integração - NLI em 85 dB(A) nas horas-extras.

- Altíssima compressão das energias de forma artificial, meramente algébrica, via $q=5$, que faz com que a energia verdadeira de 4.724,63\% seja computada, falsamente, como $869,31 \%$ no caso do trabalhador "C". Ou seja, uma compressão descomunal de 5,43 vezes.

Tem-se, então, que a adoção desses dois parâmetros (NLI > $85 \mathrm{~dB}(\mathrm{~A})$ e q=5) autoriza uma fraude para muito além do direito, uma fraude científica com repercussões catastróficas ao trabalhador. Lembrando que nos patamares ruidosos do exemplo, o marcador não é a surdez, ainda que para ela convirja, mas a amputação, a lesão, o acidente e a morte, pois os efeitos extra auditivos do ruído relacionados aos distúrbios e disfunções cardíacas, circulatórias, hormonais, psíquicas, emocionais inevitavelmente a eles dão causam. 
Por tudo até aqui exposto, o uso das fórmulas, tabelas e exemplos acima, baseados no Anexo I da NR 15, é equivocado e não deve ser aplicado quando o objeto investigado é a prevenção ou ainda o bem jurídico tutelado é o benefício de aposentadoria precoce por exposição (INSS), com repercussão tributária relacionada ao FAE (RFB), isso porque para tais situações, devem-se usar a norma NHO 01 da Fundacentro e seus parâmetros, na íntegra.

\section{CONSIDERAÇÕES FINAIS}

A título de considerações finais, registre-se que, a despeito do conhecimento neste artigo compilado, coexistem, quanto ao fator de risco ruído, um barulho normativo e um silêncio governamental, muito possivelmente pelas influências dos detentores dos meios de produção em não assumir posturas preventivas e inverter ativos para a melhora dos ambientes ruidosos ao embaraçar atualização normativa no campo do tripartismo. Nesse contexto, o governo brasileiro silencia ante flagrante necessidade de uniformização de norma, pois o que vale para RFB e INSS não vale para MTb, quando a matéria é o fator de risco ruído contínuo ou intermitente. Causa estupefação, daí a referência ao termo barulho, que as normas da Fundacentro, entidade vinculada ao MTb, não goze coercitividade para fins das tutelas por este reguladas, sendo meramente recomendatórias, enquanto que para RFB e INSS tais normas sejam de cumprimento obrigatório.

No tocante ao eSocial, registre-se que os campos de SST relativos à intensidade, concentração, metodologia, procedimento, EPI e EPC se referem às normas previdenciárias e tributárias emanadas das normas de regência em vigor que obrigam a empresa informar à União Federal; diferentemente da norma trabalhista, que não impõe essa obrigação informacional. Por isso, todos esses campos dizem respeito apenas à RFB e ao INSS. Toda procedimentalização e metodologia relativa ao 
pagamento de adicional de insalubridade por ruído é feita apartada e sem se comunicar com os eventos do eSocial, devendo a empresa apenas informar, por NIT, se há ou não pagamento declarado para essa rubrica.

Atualmente, e desde 01 janeiro de 2004, está em vigor o RPS (Decreto 3048/99) alterado pelo Decreto ${ }^{\circ}$ 4.882/2003. Este último fez uma reestruturação conceitual, retificando as falhas dos decretos anteriores, ao adotar o fator de dobra 3 ( $q=3$ ), a metodologia e procedimentos da $\mathrm{NHO} 01$ da Fundacentro e, principalmente, a definição de Nível de Exposição Normalizado - NEN com limite de tolerância considerado igual ou acima 85 (oitenta e cinco) dB (A). Dessa forma, acabou com o erro de duplicação de dose que adotava $\mathrm{q}=5$ e transformou uma norma recomendatória em norma mandatória para fins de INSS e RFB, vinculando os limites de tolerância, medições, procedimentos, equipamentos, certificação e metodologia à NHO 01 Fundacentro. Todavia, tais regras vigoraram até 31 de dezembro 2003. É bom ter em mente que a norma do INSS referida pela IN 971 da RFB deve sempre ser aquela vigente, ainda que haja ultratividade, pois como discorrem sobre interpretação, segundo Código Tributário Nacional - CTN, tais dispositivos retroagem, conforme preceitua o art. 106 do CTN.

Destaque-se que não há celeuma quanto ao ponto de disparo do nível de ação, pois a própria NHO 01 considera como nível de ação o valor NEN igual a $82 \mathrm{~dB}(\mathrm{~A})$. Como os parâmetros corretos são aqueles definidos pela NHO 01 da Fundacentro, tem-se que o fator de dobra é $3 \mathrm{~dB}$, sendo que a metade de $85 \mathrm{~dB}$ (A) é $82 \mathrm{~dB}(\mathrm{~A}), \log$, o nível de ação dispara a partir de $82 \mathrm{~dB}(\mathrm{~A})$.

Outro ponto a sedimentar diz respeito ao nível limiar de Integração, pois a NR 15 tem sido erroneamente interpretada ao elevá-lo para $85 \mathrm{~dB}(\mathrm{~A})$, deixando de fora as cargas ruidosas agressivas abaixo disso. Retome-se que a tabela original indicava Nível 
Limiar de Integração = $80 \mathrm{~dB}(\mathrm{~A})$, que correspondia a $16 \mathrm{~h}$ de jornada (no máximo). Os técnicos da Fundacentro sinalizaram com o aceite desse limite, todavia o setor jurídico do MTE não acatou a recepção dessas linhas da tabela, argumentando que a carga horária máxima permitida era de $8 \mathrm{~h}$ e não faria sentido previsão de limites para tempos superiores. Desse modo, os tempos máximos permitidos para exposição superiores a $80 \mathrm{~dB}(\mathrm{~A})$ e inferiores a $85 \mathrm{~dB}(\mathrm{~A})$ foram simplesmente excluídos quando da importação do normativo estadunidense. Esse argumento do setor jurídico já era temerário à época, mas, desde 1988, não se sustenta, por conta da CRFB-88, que expressamente prevê realização de horas-extras. Sabe-se qual é a equação a partir da qual se construiu o Anexo I da NR-15 do MTE, logo, é perfeitamente factível suprir as lacunas da norma e praticar o limiar de integração a partir de $80 \mathrm{~dB}(\mathrm{~A})$. Reforce-se o exemplo ao se determinar ao trabalhador 4 horas-extras a jornada de $8 \mathrm{~h}$, tem-se um tempo total de $12 \mathrm{~h}$ ( $\mathrm{T}=12 \mathrm{~h}$ ), submetido, por exemplo, a uma energia média (Lavg) de $92 \mathrm{~dB}(\mathrm{~A})$. Nesse caso, obtém-se:

$$
\begin{aligned}
& \mathrm{T}(\mathrm{h})=\frac{16}{2 \frac{\operatorname{Lavg}-80}{5}} \rightarrow \text { operando a álgebra de logaritmos } \rightarrow \text { Lavg }=5 \mathrm{x}\left(\frac{\log \left(\frac{16}{\mathrm{~T}}\right)}{\log 2}\right)+80 \rightarrow \\
& \text { Lavg }=5 \times\left(\frac{\log \left(\frac{16}{12}\right)}{\log 2}\right)+80 \rightarrow \text { Lavg }=5 \times\left(\frac{\log (1,33)}{\log 2}\right)+80 \rightarrow 82 \mathrm{~dB}(\mathrm{~A})
\end{aligned}
$$

Assim, para $12 \mathrm{~h}$ de trabalho, tem-se um nível sonoro médio de Lavg $=82 \mathrm{~dB}(\mathrm{~A})$. Como essa energia está entre $85 \mathrm{~dB}(\mathrm{~A})$ e $80 \mathrm{~dB}(\mathrm{~A})$, ela não deve ser descartada. Deve-se usar a fórmula para suprir a lacuna da tabela do Anexo I da NR 15. Na mesma esteira, por exemplo, Lavg de $83 \mathrm{db}(\mathrm{A}) \rightarrow \mathrm{T}(\min )=\frac{16}{2^{\frac{18-80}{5}}}=10 \mathrm{~h}$ que implica o máximo duas horas extras. Analogamente, para níveis de Lavg de 80 dB(A) $\rightarrow \mathrm{T}(\min )=\frac{16}{2^{\frac{80-80}{5}}}=8 \mathrm{~h} \quad$ cujo máximo esbarra em oito extras. Assim sucessivamente, conforme se apresenta na figura seguinte. 
Figura 7: Carga ruidosa descartada para fins de pagamento de horasextras ou quando se expõe a menos de $85 \mathrm{~dB}(\mathrm{~A})$

\begin{tabular}{|r|l|}
\hline $\begin{array}{c}\text { Nivel de nuido } \\
\text { dB (A) }\end{array}$ & $\begin{array}{c}\text { Máxima } \\
\text { exposiçä́o diánia }\end{array}$ \\
\hline 80 & 16 horas \\
\hline $\mathbf{8 1}$ & $\mathbf{1 4}$ horas \\
\hline $\mathbf{8 2}$ & $\mathbf{1 2}$ horas \\
\hline $\mathbf{8 3}$ & $\mathbf{1 0}$ horas \\
\hline 84 & 09 horas \\
85 & 08 horas \\
\hline
\end{tabular}

Fonte: próprio autor

Arremata-se, portanto, que para fins de adicional de insalubridade é necessário aplicar as fórmulas e suprir o intervalo faltante no Anexo I da NR 15, entre $85 \mathrm{~dB}(\mathrm{~A})$ e 80 $\mathrm{dB}(\mathrm{A})$, fazendo uso da tabela com os valores acima. Ou seja, depreende-se que os seguintes parâmetros devem ser operados à luz da CRFB-88 no que concerne exclusivamente ao adicional de insalubridade: Nível limiar de integração $=80 \mathrm{~dB}(\mathrm{~A})$ e Incremento de duplicação de dose $\mathrm{q}=5$.

Finalmente, considerando a necessidade de uniformização da legislação referente a ruído, no âmbito da União Federal, por tudo aqui exposto, sugerem-se algumas medidas que além de fazer justiça social, produzirão justiça fiscal, e, principalmente, segurança jurídica às empresas. Nesse sentido, são sugeridas as seguintes medidas saneadoras:

- Aproveitar este ensaio no âmbito dos documentos técnicos pertencentes ao acervo público do eSocial de modo a lhe conferir um suporte técnico específico que embase as decisões relacionadas ao fator ruído. 
- Estabelecer revogação por parte do MTE do Anexo I da NR 15, substituindoo pela norma NHO 01 da Fundacentro, tornando-a mandatório como já o fez a RFB e o INSS, notadamente para avançar na pacificação, pois, como está hoje, todo ambiente de trabalho que enseje pagamento de adicional de insalubridade por ruído necessariamente ativará norma da RFB e INSS, todavia não o contrário, pois é possível que pela NHO 01 se ultrapasse dose unitária (limite de tolerância), mas não ative insalubridade trabalhista. Isso se impõe da perspectiva do direito e da ciência, pois como visto o Anexo I da NR 15, além de obsoleto e anacrônico, está errado.

- Estabelecer revogação da alínea "a" do Art 280 da IN 77/15 do INSS, por contrariar abertamente o caput, ao dispor de outros limites de tolerância que não aquele definido (NEN):

Art. 280 - A exposição ocupacional a ruído dará ensejo a caracterização de atividade exercida em condições especiais quando os níveis de pressão sonora estiverem acima de oitenta dB (A), noventa $\mathrm{dB}(\mathrm{A})$ ou 85 (oitenta e cinco) $\mathrm{dB}(\mathrm{A})$, conforme o caso, observado o seguinte:(...) IV - a partir de 01 de janeiro de 2004, será efetuado o enquadramento quando o Nível de Exposição Normalizado - NEN se situar acima de 85 (oitenta e cinco) dB (A) ou for ultrapassada a dose unitária, conforme NHO 1 da Fundacentro, sendo facultado à empresa a sua utilização a partir de 19 de novembro de 2003, data da publicação do Decreto no 4.882 , de 2003, aplicando:

a) os limites de tolerância definidos no Quadro do Anexo I da NR15 do MTE; e

b) as metodologias e os procedimentos definidos nas NHO-01 da Fundacentro.

- Retificar do Manual de Perícia Médica, aprovado pela Resolução 600/17 do INSS, ao se basear na contaminada alínea "a" do Art. 280 da IN 77/15, repete o vício de insubordinação perante o decreto ao considerar equivocadamente 
NLI de $85 \mathrm{~dB}(\mathrm{~A})$ e $\mathrm{q}=5$, com o agravante de aprofundá-lo, por introduzir elemento estranho à formula do NEN da NHO 01 da Fundacentro. No bojo dessa retificação, sugere-se considerar:

- Excluir do Manual de Perícia Médica toda e qualquer menção, direta ou indireta ao Anexo I da NR 15 do MTE.

- Excluir do Manual de Perícia Médica toda e qualquer menção, direta ou indireta ao fator de dobra $\mathrm{q}=5$ e NLI de $85 \mathrm{~dB}(\mathrm{~A})$, deixando claro que os parâmetros corretos são: fator de dobra q=3 e NLI de $80 \mathrm{~dB}(\mathrm{~A})$, nos termos da NHO 01 da Fundacentro.

- Corrigir página 88 daquele manual suprimindo o termo 16,61 da fórmula NEN $=\mathrm{NE}+16,61 \times 10 \log \mathrm{TE} / 480[\mathrm{~dB}]$, pois o correto é: $\mathrm{NEN}=\mathrm{NE} \times 10 \log$ $\mathrm{TE} / 480[\mathrm{~dB}]$

- Fazer errata na página 88 de Manual, colocando-se um leia-se: VI - para NHO 01 utiliza-se "9,6" onde se lê: VI - para NHO 01 utiliza-se "9,96".

\section{REFERÊNCIAS BIBLIOGRÁFICAS}

[1] Almeida, H. (1950). Influence of electric punch card machines on the human ear. Archives of Otolaryngology. N. 51. p. 215-222.

[2] Vieira, K. G. (2003). Perda da força sofrida pelo arco do equipamento de proteção individual auricular tipo concha de acordo com o tempo de utilização. (Curso de Especialização em Engenharia de Segurança do Trabalho), Unesp, Bauru/SP.

[3] Souza, N. S. S. (2001). Hipertensão arterial entre trabalhadores de petróleo expostos a ruído. Cad. Saúde Pública. Vol. 17, N. 6. pp.1481-1488. 
[4] Andren, L. et al. (1982). Effect of noise on blood pressure and 'stress' hormones. Clinical Science. Vol. 62. pp.137-141.

[5] Harlan, W. R. (1981). Impact of the environment on cardiovascular disease: Report of the American Heart Association task force on environment and the cardiovascular system. Circulation. Vol. 63. pp. 243A-246A.

[6] Santos, U. P. et al. (1996). Ruído: Riscos e Prevenção. 2. ed. São Paulo: Hucitec.

[7] Brasil. Ministério do Trabalho. Norma Regulamentadora 15 - Atividades e Operações Insalubres. Disponível em: <http://sislex.previdencia.gov.br/paginas/05/mtb/15.htm>. Acesso em: 17 set. 2017.

[8] ACGIH. http://www.acgih.org/ Acesso em: 17 set. 2017.p. 6-9.

[9] ISO-1999/1990: The statement in the occupational exposure limit that the proposed OEL $(85 \mathrm{~dB}(\mathrm{~A}))$ will protect the median of the population against a noiseinduced permanent threshold shift (NIPTS) after 40 years of occupational exposure exceeding $2 \mathrm{~dB}$ for the average of $0.5,1,2$, and $3 \mathrm{kHz}$.

[10] Soto, J.M.O.G. et al. (2010). Artigo Técnico publicado pela Revista ABHO, Vol. 9, N. 21.

[11] ACGIH. American Conference of Governamental Industrial Hygiene. (1958). Limites de Exposição (TLVs) para Substâncias Químicas e Agentes Físicos e Índices Biológicos de Exposição (BELs). Tradução ABHO - Associação Brasileira de Higienistas Ocupacionais. Cincinnati. Disponível em: <http://www.acgih.org/>. Acesso em: 17 set. 2017.

[12] Vasconcelos, F.D. (1995). Uma visão crítica do uso de padrões de exposição na vigilância da saúde no trabalho. Cadernos de Saúde Pública, Vol. 11, N. 4. P. 588599. Disponível em: <https://dx.doi.org/10.1590/S0102-311X1995000400007>. Acesso em: 25 set. 2017.

[13] Arcuri, A. S. A., Cardoso, L. M. N. (1991). Limite de Tolerância? Revista Brasileira de Saúde Ocupacional. Vol. 19. N. 74. pp. 99-106.

[14] ACGIH. American Conference of Governamental Industrial Hygiene. (1976). Documentation of the Threshold Limit Values and Biological Exposure Indices. Vol. 1.p. 01-718.

[15] Pinto, T. C. N. O., Silva, M. C. E. S. P. (2004). Analisando os Limites de Tolerância brasileiros. In: II Congresso Nacional de Excelência em Gestão, Rio de Janeiro. Disponível em: <http://www.inovarse.org/filebrowser/download/9051>. Acesso em: 20 set. 2017. 